\title{
Online Betting Intensity is Linked with Extraversion and Conscientiousness
}

\section{Palomäki, Jussi Petteri}

$2021-10$

Palomäki , J P , Laakasuo , M , Castrén , S , Saastamoinen, J , Kainulainen , T \& Suhonen , N 2021, ' Online Betting Intensity is Linked with Extraversion and Conscientiousness ' , Journal of Personality , vol. 89 , no. 5 , pp. 1081-1094 . https://doi.org/10.1111/jopy.12637

http://hdl.handle.net/10138/336736

https://doi.org/10.1111/jopy.12637

cc_by

publishedVersion

Downloaded from Helda, University of Helsinki institutional repository.

This is an electronic reprint of the original article.

This reprint may differ from the original in pagination and typographic detail.

Please cite the original version. 


\title{
Online betting intensity is linked with Extraversion and Conscientiousness
}

\author{
Jussi Palomäki $^{1}$ (D) | Michael Laakasuo ${ }^{1}$ | Sari Castrén ${ }^{2,3,4}$ | Jani Saastamoinen ${ }^{5}$ | \\ Tuomo Kainulainen $^{5}$ | Niko Suhonen ${ }^{5}$
}

${ }^{1}$ Cognitive Science, Department of Digital Humanities, Faculty of Arts, University of Helsinki, Helsinki, Finland

${ }^{2}$ Department of Public Health Solutions, Alcohol and Drugs and Addictions Unit, Finnish Institute for Health and Welfare, Helsinki, Finland

${ }^{3}$ Department of Public Health, Faculty of Medicine, University of Helsinki, Helsinki, Finland

${ }^{4}$ Faculty of Social Sciences, Department of Psychology and Speech-Language Pathology, University of Turku, Turku, Finland

${ }^{5}$ Business School, Joensuu Campus, University of Eastern Finland, Joensuu, Finland

\section{Correspondence}

Jussi Palomäki, Cognitive Science, Department of Digital Humanities, Faculty of Arts, University of Helsinki, Helsinki, Finland.

Email: jussi.palomaki@helsinki.fi

\section{Funding information}

Emil Aaltosen Säätiö, Grant/Award Number: \#331102; Jane ja Aatos Erkon Säätiö; The Finnish Foundation for Alcohol Studies, Grant/Award Number: \#AM13766; Academy of Finland, Grant/Award Number: \#323207

\begin{abstract}
Introduction: Extraversion and Conscientiousness are well-studied personality traits associated with reward processing and goal prioritization, respectively, and bear on individual differences in financial risk-taking. Using unique large datasets, we investigated the link between these traits and male online gamblers' actual betting participation and intensity.
\end{abstract}

Method: We combined datasets containing online horse betting data (during 20152016) from the Finnish monopoly betting company, administrative registry data from Statistics Finland, and personality trait measures from the Finnish Defence Forces corresponding to Extraversion and Conscientiousness as defined in the five-factor model. We modelled associations between these traits and betting participation $(n=471,968)$ and intensity $(n=11,217)$ among male horse bettors (age $=36-53)$.

Results: Controlling for demographics and IQ, individuals scoring high on Conscientiousness (or Extraversion) were less (or more) likely to bet and less (or more) intensive bettors - even when personality was measured 16-34 years before betting occurred. One $S D$ personality score increase represented an annual decrease (Conscientiousness) or increase (Extraversion) of €570-754 in spending.

Conclusions: Extraversion and Conscientiousness are implicated in real-life financial behavior with tangible consequences for individuals. These effects are stronger than for many known demographic variables used in gambling studies and persist up to 34 years after personality has been measured.

\section{K E Y W O R D S}

betting intensity, horse race betting, male, online gambling, personality

\section{1 | INTRODUCTION}

"A racehorse is an animal that can take several thousand people for a ride at the same time."Folk saying
Be it sports (Castanier et al., 2010; Merritt \& Tharp, 2013) or financial risk-taking (Ishfaq et al., 2020; Oehler et al., 2018; Wong \& Carducci, 2013), high Extraversion and low Conscientiousness are consistently associated with high risktaking in life-style choices. Both traits covary with individual

This is an open access article under the terms of the Creative Commons Attribution License, which permits use, distribution and reproduction in any medium, provided the original 
differences in impulsivity and self-control (Mao et al., 2018), and they are fundamentally linked with people's tendencies of making financial decisions, taking (controlled or detrimental) risks, and generally keeping their lives on track (Nicholson et al., 2005). In this study, we propose that Extraversion is linked to motivation for reward, and Conscientiousness to selecting and prioritizing the things that are felt rewarding. Using large datasets, we analyze how this trait dynamics manifests within individual differences in actual online horse race betting.

\section{1 | Extraversion and reward processing}

Extraverts are outgoing, enthusiastic, talkative, assertive, like the company of others, and generally have a positive view of events (Fishman et al., 2011). Research over the last few decades suggests that the major construct of Extraversion comprises two parts, agency (relating to achievement-striving and social dominance) and affiliation (relating to positive affect, and enjoying interpersonal bonds), both of which are conceptually linked to reward sensitivity (Depue \& Collins, 1999; Smillie, 2013; Wacker \& Smillie, 2015). According to this view, extraverted individuals engage in social situations because they are inherently rewarding (Lucas et al., 2000; but see Ashton et al., 2002 for criticism). Moreover, behaviors such as altruism and feelings such as empathy-which are social but do not clearly involve approaching rewards-are more associated with trait Agreeableness than Extraversion (Smillie, 2013).

Agentic Extraversion appears to be mostly about the desire for rewards, which is mediated by the brain's dopamine system, while affiliative Extraversion is associated with the enjoyment of rewards (e.g., contentment), which, in turn, is mediated by the endomorphin/opioid system (e.g., Berridge \& Robinson, 1998; Smillie, 2013). Research using pharmacological and brain imaging methods have found that Extraversion (as a uniform construct) was positively correlated with hormonal responses to a selective dopamine D2 receptor agonist (e.g., Depue, 1995), and linked with activity in the brain's reward areas in response to monetary rewards (e.g., Wu et al., 2014). Studies have also linked Extraversion with, for example, polymorphisms of the dopamine D2 and D4 receptor genes, although the overall evidence from brain imaging and molecular genetics remains inconclusive; for example, the distinction between agentic and affiliative Extraversion has not been thoroughly explored in such work (for a review, see Wacker \& Smillie, 2015; see also Civai et al., 2016; Smillie et al., 2011).

Because Extraversion is associated with reward mechanisms, extraverted individuals seek both social and nonsocial rewards more actively than introverted individuals (Depue \& Collins, 1999). In line with the reward processing view, Extraversion has been positively associated with risk-seeking in investment decisions (Oehler \& Wedlich, 2018) as well as gambling involvement, such as playing multiple game types, and high number of years spent gambling (Laakasuo et al., 2014; Savage et al., 2014). Finally, impulsivity, a subfactor of Extraversion (and expression of low Conscientiousness), is a known risk factor associated with gambling related harms (Blaszczynski \& Nower, 2002; Leeman \& Potenza, 2012).

\section{2 | Conscientiousness and goal prioritization}

Conscientiousness-being careful, diligent, dutiful and deliberate-has, in turn, been strongly linked with reduced impulsivity and increased self-control (Mao et al., 2018). There is an established beneficial link between self-control and physical health, lack of substance dependence, personal finances as well as lack of criminal offending outcomes (Moffitt et al., 2011). In addition, both Conscientiousness and financial literacy have been found to be consistent predictors of asset accumulation (Letkiewicz \& Fox, 2014); Conscientiousness was linked with increased risk-aversion in investment decisions (Oehler \& Wedlich, 2018); and further evidence in gambling research shows that Conscientiousness may reduce harmful gambling involvement due to careful and diligent financial management (Bagby et al., 2007; Brunborg et al., 2016; Karre et al., 2009; MacLaren et al., 2011). Similarly, high impulsivity is strongly linked with problem gambling (Devos et al., 2020; Hodgins \& Holub, 2015; Nower \& Blaszczynski, 2006). In a nonclinical setting, using the Iowa Gambling Task, individuals who failed to learn the consequences of their poor decisions seemed to be more impulsive than those who performed well (Davis et al., 2007); and, finally, Soane et al. (2010) found that Conscientiousness was negatively associated with risk-taking and likelihood of risk-related choices across health, gambling, and recreational domains.

Conscientiousness is associated with cortical thickness in several brain regions (Lewis et al., 2018), many of which overlap with a system labelled as the Goal Priority Network (GPN; comprising the anterior insula, dorsal anterior cingulate cortex, and dorsolateral prefrontal cortex; Rueter et al., 2018). The GPN hypothesis of Conscientiousness proposes that the ability to control one's life and surroundings is at least partially explained by the brains of conscientious individuals having more synchronous communication within the GPN. Ostensibly, there is less coordination loss between brain areas for conscientious individuals, which, in turn, makes it easier for them to prioritize between multiple goals.

While Conscientiousness and general intelligence are often uncorrelated in research, they seem to tap overlapping neural resources. Both utilize the prefrontal cortex (PFC), the 
area of the central nervous system whose size has increased the most during the natural history of the homo sapiens (e.g., Dunbar, 1998). However, the PFC consists of several distinct subnetworks, one of which is associated with at least working memory and IQ, but not Conscientiousness (DeYoung et al., 2009; Rueter et al., 2018).

Nonetheless, several studies have associated Conscientiousness with the thickness of the dorsolateral PFC (part of the GPN) - an area responsible for maintaining and activating symbolic or nonconcrete goals, and for planned action sequences based on conceptual understanding of rules and norms (DeYoung et al., 2009; Kapogiannis et al., 2013). In a related study, Conscientiousness was associated with the medial surface of the PFC (also part of the GPN; Adelstein et al., 2011; Yeo et al., 2011). These results imply that moving attention away from distraction towards goal attainment is central in Conscientiousness (Fox et al., 2006). DeYoung (2015) suggested that Conscientiousness may involve complex regulatory functions concerning reward-seeking and defensive motivational systems, which, in turn, relate to Extraversion and Neuroticism. He further speculated that the expression of Conscientiousness is context-dependent: Sometimes Conscientiousness may suppress immediate or hedonistic emotional reactions so that more idealized or abstract goals can be pursued; at other times Conscientiousness might enhance attentional binding to threatening or emotionally hedonistic cues, if they are in alignment with one's abstract goals.

\section{3 | Current study}

In general, studies seem to converge on the view of Extraversion and Conscientiousness as central traits in reward processing and life management, including aptitude in financial decision-making, and avoiding unnecessary and negligent risk-taking. Both traits have also been implicated in research on risk-taking and gambling involvement, which is sensible given the salience of monetary rewards in gambling. If Extraversion is about motivation for rewards, Conscientiousness is about selecting and prioritizing the things that are felt rewarding.

Given this evidence, Extraversion and Conscientiousness are ideal focus points to evaluate on a population level, using large datasets, how individual differences in personality predict actual financial decisions. Many existing studies on individual differences in personality, as well as gambling studies, rely largely on self-report surveys, which are problematic due to participants' self-selection into the surveys and various social biases (e.g., Fisher, 1993). While self-reporting is currently the best-known way to measure personality, gambling behavior can be directly observed in online gambling data. Unfortunately, these data are typically detached from the bettors' psychological attributes such as personality. To get a better understanding of the effects of personality traits on behavior, research should focus on observed instead of selfreported behavior.

Moreover, while personality traits have considerable continuity over time, they also change in systematic ways, and the predictive power of personality across time is not fully understood. For example, as people age, they tend to become more socially dominant, more conscientious, and more emotionally stable (Damian et al., 2019; Roberts \& DelVecchio, 2000; Roberts et al., 2006; Robins et al., 2001); but there may also be high individual variability in personality change, as some people may remain unchanged, while others change substantially (Beck \& Jackson, 2020).

Here, we combined individual-level data from three sources, including personality trait data from the Finnish Defence Forces (FDF), online horse betting data from the Finnish monopoly betting company, and administrative registry data on the Finnish population from Statistics Finland. Our combined datasets enabled us to not only link large population-level datasets to actual horse race betting behavior but also evaluate whether personality, when measured several decades ago, can still meaningfully predict behavior.

Online sports betting is an important part of the gambling industry and offers an excellent platform to study actual financial decisions: it comprises over $40 \%$ of all online gambling (European Gaming and Betting Association, 2018) and is likely to grow in future (Parke \& Parke, 2019; Rodríguez et al., 2017). While a form of gambling, sports betting also resembles consumer behavior (Paul \& Weinbach, 2011), meaning that sports bettors tend to be recreational gamblers who consume gambling products for various reasons, such as seeking hedonic pleasure instead of merely financial gain (Cotte, 1997); and sports bettors often bet on the match to make the game appear more exciting and intense (Killick \& Griffiths, 2021).

To sum, existing research and theory suggests that Extraversion is strongly linked to reward processing, while Conscientiousness is associated with diligence and dutifulness in money management, as well as reduced out-ofcontrol risk-taking. Winning money in a betting environment can be seen as highly rewarding and pleasurable (much like consumption of pleasurable goods). On the other hand, as a form of gambling, betting on horse races can also be viewed as risky financial decision-making (Armstrong \& Carroll, 2017). Thus, we propose that Extraversion and Conscientiousness - or more precisely their FDF personality test counterparts-are positively and negatively, respectively, associated with the volume and frequency of betting money in online horse races, as well as the likelihood of being a bettor. In other words, we expect individuals with high Extraversion scores to be active bettors with high annual and daily betting volume, and, conversely, we expect the reverse for individuals 
with high Conscientiousness scores. Our aim is to provide a reliable description of how personality predicts actual betting involvement across decades while simultaneously controlling for various, theoretically relevant, socioeconomic attributes.

\section{2 | METHOD}

\subsection{Design and participants}

We ran a cross-sectional analysis by linking male bettors' online betting behavior with their personality traits. Our data set combined individual-level (1) personality trait data from the FDF, (2) online horse betting data from Fintoto Ltd (a state-owned gambling monopoly, currently known as Veikkaus Ltd), and (3) administrative registry data from Statistics Finland. The total sample of potential bettors included 471,968 males aged 36-53 accounting for $74.5 \%$ of Finnish males in the age group. Of these, 11,217 were online horse bettors. This study has been approved by the University of Eastern Finland's Committee on Research Ethics.

\subsubsection{FDF personality trait data}

The personality trait data consist of individuals who took their military service between 1982 and 2000. In Finland, military service is mandatory for males and voluntary for females who account for $2 \%$ of the conscripts. Hence, our subsample includes 471,968 males born between 1962 and 1979. Most carry out their service at the age of 19 or 20 after finishing secondary education. The FDF administers intelligence quotient (IQ) and personality tests to all conscripts at the beginning of service to screen potential candidates for noncommissioned officer training. The personality trait test remained constant between 1982 and 2000.

The personality test measures the subtraits of (a) achievement striving, (b) activity-energy, (c) deliberation, (d) dutifulness, (e) leadership motivation, (f) masculinity, (g) self-confidence, and (h) sociability. There are between 18 and 33 items (i.e., statements) evaluated on a "yes/no" scale for each subtrait (218 items in total). Overall personality scores are the sum of all statements a person agrees with (or disagrees with in case of reverse-coded items). Only the overall scores were disclosed by the FDF. The internal reliabilities of the personality test and its subtraits as measured by Cronbach's alpha range from .6 to .9 (average $=.75$; for further details, see Jokela et al., 2017; Nyman, 2007).

Jokela et al. (2017) demonstrated the convergent validity between the FDF personality measure and the FFM: Most of the FDF traits were related to Conscientiousness and Extraversion. ${ }^{1}$ Thus, we formed two personality constructs, based on principal component analysis (PCA), reflecting
Conscientiousness (deliberation, achievement striving and dutifulness) and Extraversion (leadership motivation, activity-energy and sociability) in the FFM.

In addition, since we had information on composite IQ test scores (comprising Visuospatial, Verbal, and Maths IQ), we added a variable measuring IQ in the empirical models as a control variable. Suhonen et al. (2020) have analyzed empirical relations between betting consumption and IQ in more detail using the same data sources of IQ and betting data, and thus, the IQ results are not in the focus of the current article.

\subsection{2 | Betting data}

The betting data contain all online horse race bets made by an individual bettor at the betting company's online platform between September 1, 2015, and August 31, 2016. In total, there were 47,324 bettors ( $75.5 \%$ male), of which we had personality trait data on 11,217 men aged between 36 and 53. Our key variables in empirical analyses are whether an individual participates in betting activity at all (an individual either has or does not have an online betting account, which they have used for betting), total amount staked daily and annually, and the number of betting days during the 1-year observation period.

\subsubsection{Administrative registry data on demographics}

The data were registered in 2015 for administrative purposes and contain several measures of individuals' socioeconomic background. They cover the entire Finnish population aged between 15 and 70 (3.92 million). Data from Statistics Finland are of high quality with few missing values. We use age, education level, income, socioeconomic and marital status, number of children, and municipality of domicile as control variables in our analyses. These variables were selected based on prior literature examining links between socioeconomic background and gambling/personality (Brunborg et al., 2016; Mora-Salgueiro et al., 2021; Salonen et al., 2020).

\subsection{Data analysis}

Our analyses are based on two separate samples. First, we modeled participation in online horse betting using all males with available FDF test scores $(n=471,968)$. If a person used his betting account for betting purposes during the 1-year observation period, he was interpreted as a horse bettor. We used probit regression to estimate how Conscientiousness and 
Extraversion scores were associated with the probability of being an online horse bettor. Second, we used ordinary least squares (OLS) regression to estimate how Conscientiousness and Extraversion scores predict online horse bettors' betting intensity $(n=11,217)$. The following dependent variables were calculated as indicators of betting intensity: (1) betting volume (annual total amount staked in euros), (2) the number of days played, and (3) bets placed per day in euros. In the analyses, betting volume, the number of days played, and bets placed per day are log-transformed to normalize their distributions. ${ }^{2}$ Socioeconomic variables and IQ were used as controls.

We also calculated Bayes factors for OLS regression model selection (models predicting betting intensity) based on the method and priors ${ }^{3}$ presented in Rouder and Morey (2012) and Liang et al. (2008). First, we calculated the Bayes factors between multiple submodels (that included various combinations of covariates) and the (intercept only) null model. Then, we computed the Bayes factor of each model relative to the full model that included Extraversion, Conscientiousness, IQ, and the demographic variables listed above plus two additional demographic variables (religiosity, and a dichotomous variable "Swedish speaker" indexing whether the individual's native tongue was Swedish, the second official language in Finland). These analyses are detailed in Table S9 and Figure S5. In short, the Bayes factor-based evidence most strongly supported fitting models using Extraversion, Conscientiousness, IQ, and the sociodemographic variables except religiosity and Swedish speaker, as covariates.

\section{3 | RESULTS}

\section{1 | Descriptive statistics}

Approximately $2.4 \%$ of male population with available FDF test scores participated in online horse betting. Table 1 reports the mean (median) values for betting volume, number of days played, and bets placed per day, which were $€ 4,552$ ( $€ 306$ ), 59 (17), and $€ 48$ (€19), respectively. Table 2 shows the results of the PCA. The personality variables (Conscientiousness, Extraversion) are the regression coefficients of standardized principal component factor scores (mean $=0, S D=1)$ calculated from the FDF personality subtraits. Both factors exhibit high factor loadings and good internal consistency, with Cronbach's alphas of .746 (Conscientiousness) and .856 (Extraversion). Variable definitions, histograms of personality traits for online horse bettors and for the whole sample male population, and zero-order correlations between main variables of interest are shown in Tables S1-S4 and Figures S3-S4.

\section{2 | Main results}

We first examined whether Conscientiousness and Extraversion scores predict participation in online horse betting. Then, for those who participated (bettors), we investigated linear associations between Conscientiousness and Extraversion, and betting intensity proxied by betting volume, the number of days played, and bets placed per day. All regression models included the same set of control variables. Figure 1 depicts the association between Extraversion, Conscientiousness and the probability of being a bettor (left panel shows raw data; right panel shows probit model predictions). Figure 2 depicts the associations between Extraversion, Conscientiousness and the betting intensity measures (top panel shows raw data; bottom panel shows OLS model predictions). The overall pattern of the results indicates that when socioeconomic background and IQ are controlled for, the slopes for Conscientiousness and Extraversion are negative and positive, respectively (except for the OLS model prediction for number of days played, where the slope for Extraversion is not significantly different from zero). Our main results thus suggest that males who score high on Conscientiousness (or Extraversion) are less (or more) likely to bet on online horse races, and less (or more) intensive bettors.

The left-panel of Table 3 reports the estimated average marginal effects for participation from a probit model $(1=$ bettor, $0=$ nonbettor $)$. The marginal effects are calculated for each individual at the covariate values for that individual, and these marginal effects are then averaged over all individuals. The estimated coefficients on Conscientiousness and Extraversion imply that higher scores in Conscientiousness (or Extraversion) predict a decreased (or increased) probability of being a bettor: a one standard deviation $(S D)$ increase from the mean in the Conscientiousness (or Extraversion) score decreases (or increases) the predicted probability of participation in online horse betting by $-.48(.25)$ percentage points. ${ }^{4}$ The three right-hand panels of Table 3 report coefficients for each betting intensity DV. A one $S D$ increase in the Conscientiousness score predicts a $16.6 \%^{5}(€ 754)$ reduction in annual betting volume. Increasing the Extraversion score by one $S D$ predicts a $12.5 \%(€ 570)$ increase in annual getting volume. Table S8 reports the variance decompositions of the betting intensity variables, highlighting the relative contribution of the most important model variables.

Overall, the proxies of gambling intensity are consistent with each other: Conscientiousness is a negative predictor of betting volume, days played and bets per day, whereas Extraversion is positively associated with annual betting volume and bets per day, but not with the number of days played. 
TA B LE 1 Summary statistics of dependent and independent variables

\begin{tabular}{|c|c|c|c|c|c|c|}
\hline \multicolumn{7}{|l|}{ Summary statistics } \\
\hline & $N$ & \multicolumn{2}{|l|}{ Mean } & $S D$ & \multicolumn{2}{|l|}{ Median } \\
\hline Participant & 471,968 & \multicolumn{2}{|l|}{.024} & .152 & \multicolumn{2}{|c|}{0 (Nonbettor) } \\
\hline Betting volume $(€)$ & 11,217 & \multicolumn{2}{|l|}{$4,552.12$} & $28,413.18$ & \multicolumn{2}{|l|}{306.08} \\
\hline Number of days played & 11,217 & \multicolumn{2}{|l|}{59.12} & 83.57 & \multicolumn{2}{|l|}{17.00} \\
\hline \multicolumn{7}{|l|}{ Independent variables } \\
\hline & \multicolumn{3}{|c|}{ All males $N=471,968$} & \multicolumn{3}{|c|}{ Male bettors $N=11,217$} \\
\hline & Mean & $S D$ & Median & Mean & $S D$ & Median \\
\hline Conscientiousness & .01 & .99 & .07 & -.15 & .98 & -.09 \\
\hline Composite IQ & 100 & 15 & 100.84 & 101.22 & 14.18 & 101.97 \\
\hline \multicolumn{7}{|l|}{ Socioeconomic status } \\
\hline White-collar & $39 \%$ & $49 \%$ & $0 \%$ & $35 \%$ & $48 \%$ & $0 \%$ \\
\hline Blue-collar worker & $38 \%$ & $49 \%$ & $0 \%$ & $32 \%$ & $47 \%$ & $0 \%$ \\
\hline Pensioner & $4 \%$ & $18 \%$ & $0 \%$ & $3 \%$ & $17 \%$ & $0 \%$ \\
\hline Student & $1 \%$ & $11 \%$ & $0 \%$ & $1 \%$ & $11 \%$ & $0 \%$ \\
\hline Entrepreneur & $14 \%$ & $34 \%$ & $0 \%$ & $13 \%$ & $34 \%$ & $0 \%$ \\
\hline Unemployed & $11 \%$ & $31 \%$ & $0 \%$ & $12 \%$ & $33 \%$ & $0 \%$ \\
\hline \multicolumn{7}{|l|}{ Education } \\
\hline Has no children & $38 \%$ & $49 \%$ & $0 \%$ & $42 \%$ & $49 \%$ & $0 \%$ \\
\hline Has one child & $19 \%$ & $40 \%$ & $0 \%$ & $21 \%$ & $41 \%$ & $0 \%$ \\
\hline Has two or more children & $42 \%$ & $49 \%$ & $0 \%$ & $37 \%$ & $48 \%$ & $0 \%$ \\
\hline \multicolumn{7}{|l|}{ Marital status } \\
\hline Single & $15 \%$ & $36 \%$ & .00 & $17 \%$ & $37 \%$ & $0 \%$ \\
\hline Married or cohabiting & $73 \%$ & $45 \%$ & 1.00 & $71 \%$ & $45 \%$ & $100 \%$ \\
\hline Divorced or widowed & $12 \%$ & $33 \%$ & .00 & $12 \%$ & $33 \%$ & $0 \%$ \\
\hline \multicolumn{7}{|l|}{ Municipality of domicile } \\
\hline Urban residence & $86 \%$ & $35 \%$ & $100 \%$ & $86 \%$ & $35 \%$ & $100 \%$ \\
\hline Rural residence & $14 \%$ & $35 \%$ & $0 \%$ & $14 \%$ & $35 \%$ & $0 \%$ \\
\hline
\end{tabular}

\subsection{Additional analyses}

As robustness checks, we first fit models that included only Conscientiousness and Extraversion as predictors. The results mirrored the main results presented above, although Conscientiousness was not statistically significant $(p=.12)$ in the model of bets placed per day (but its sign was still negative; see Table S5). The main models had lower BIC and
AIC values than the reduced models, suggesting that control variables should be included.

Next, we examined whether the time elapsed since the personality test was taken moderated the association between the personality traits and betting intensity as well as participation. The personality data were collected 16 to 34 years before the betting data were recorded, and statistically modelling this gap sheds light on whether the effect of personality 
T A B LE 2 Personality trait factor loadings (based on principle components) for the whole sample and the bettors separately

\begin{tabular}{|lll|} 
& \multicolumn{1}{c}{ Corresponding trait in the five-factor model } \\
\cline { 2 - 3 } FDF personality measure subtrait & Conscientiousness & Extraversion \\
\cline { 2 - 3 } Achievement striving & Bettors/whole sample & Bettors/whole sample \\
\hline Deliberation & $.737 / .759$ & $\mathrm{n} / \mathrm{a}$ \\
\hline Dutifulness & $.818 / .819$ & $\mathrm{n} / \mathrm{a}$ \\
\hline Activity-energy & $.887 / .890$ & $\mathrm{n} / \mathrm{a}$ \\
\hline Leadership motivation & $\mathrm{n} / \mathrm{a}$ & $.844 / .844$ \\
\hline Sociability & $\mathrm{n} / \mathrm{a}$ & $.917 / .916$ \\
\hline Cronbach's alpha & $\mathrm{n} / \mathrm{a}$ & $.881 / .883$ \\
\hline Lambda & $.746 / .761$ & $.856 / .856$ \\
\hline Kaiser-Meyer-Olkin measure of sampling adequacy & $1.999 / 2.038$ & $2.331 / 2.332$ \\
\hline Bartlett's test for sphericity $\chi^{2}$ & $.625 / .636$ & $.703 / .706$ \\
\hline$p$ - $v a l u e$ & $8,964 / 4.02 \times 10^{5}$ & $16,029 / 6.74 \times 10^{5}$ \\
\hline Total $N$ & $<.001$ & $<.001$ \\
\hline
\end{tabular}

Note: The loadings are calculated, based on the results of Jokela et al. (2017), separately for Conscientiousness and Extraversion (hence, the "n/a"s in the table). For PCA and robustness checks using the pooled subtraits, see Table S2, panel C.
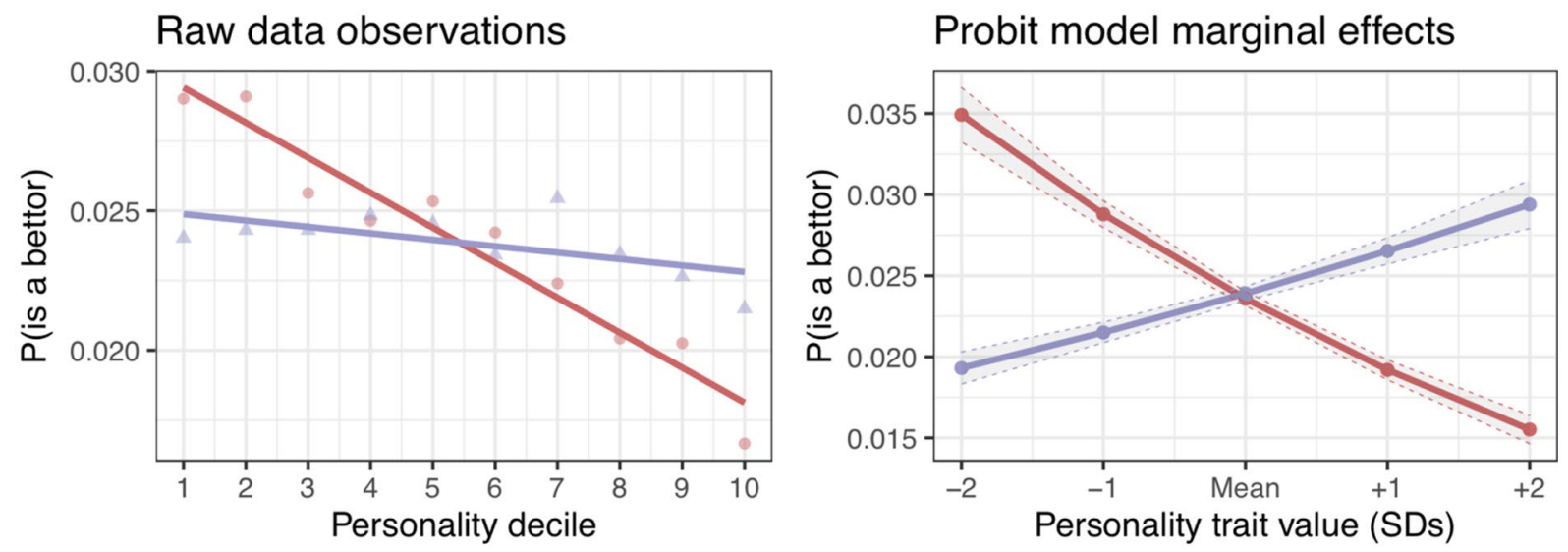

$\simeq$ Conscientiousness $\leftarrow$ Extraversion

F I G U RE 1 Personality and online horse betting participation. Left panel: Findings from the raw data on the proportion of bettors within specific personality score deciles (i.e., probability of being a bettor; slopes are fit to decile-level data). Right panel: Results from a probit regression model with a dichotomous "bettor vs. non-bettor" variable as the DV (with 95\% confidence intervals shaded), controlling for the effects of various demographic attributes and IQ (see Table 3). The ordinate depicts the probability of being a bettor for individuals with varying Conscientiousness and Extraversion scores (ranging from -2 to +2 standard deviations around the mean) [Color figure can be viewed at wileyonlinelibrary.com]

on behavior is affected by time. We modelled the interactions between (centered) time since test conducted (TTC) and Extraversion, and TTC and Conscientiousness, predicting each of our four DVs. Because participant age was extremely positively correlated with TTC $(r=.991)$, both were not entered in the same model due to unacceptably high multicollinearity. The results suggested that the time gap had no influence on our results (see Table S6 for details).

Prior literature indicates that Conscientiousness and Extraversion are positive and negative predictors, respectively, of higher education (O'Connor \& Paunonen, 2007), which, in turn, is associated with betting participation and intensity (e.g., Brunborg et al., 2016). Thus, we also tested whether level of education mediates the direct link between personality and betting participation and intensity by estimating a generalized structural equation model. We found essentially no evidence of mediation, but marginal evidence for a suppression effect whereby higher education suppressed the effects of Conscientiousness and Extraversion on annual betting volume (see Figures S1 and S2 for details). 
Raw data observations
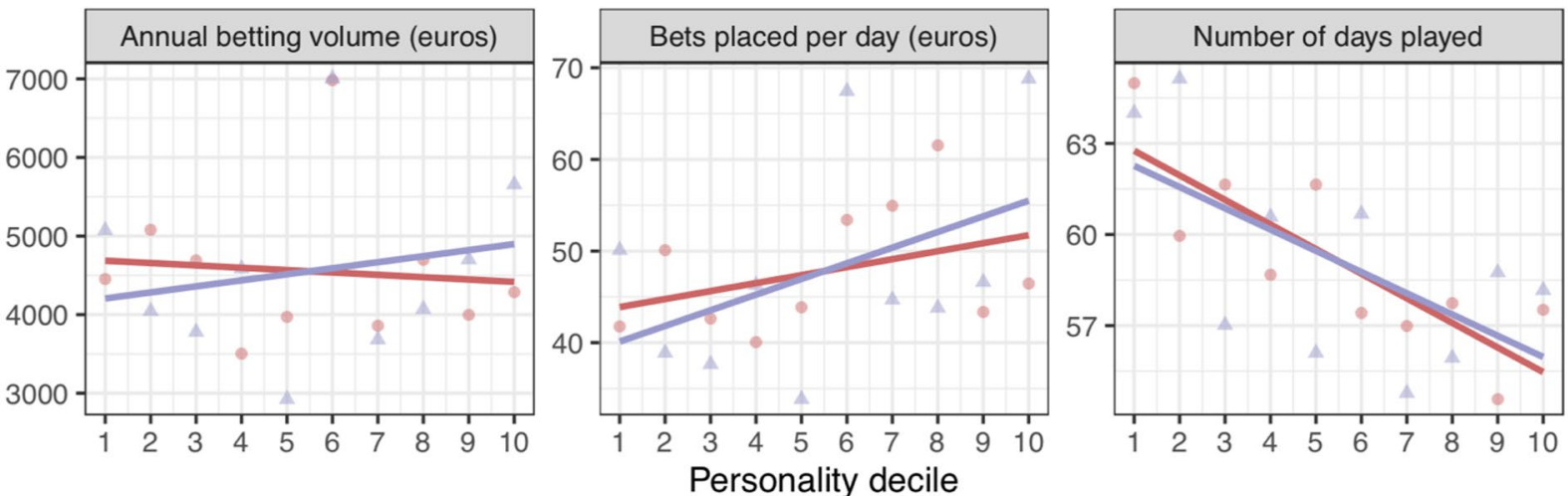

\section{Linear model predictions}
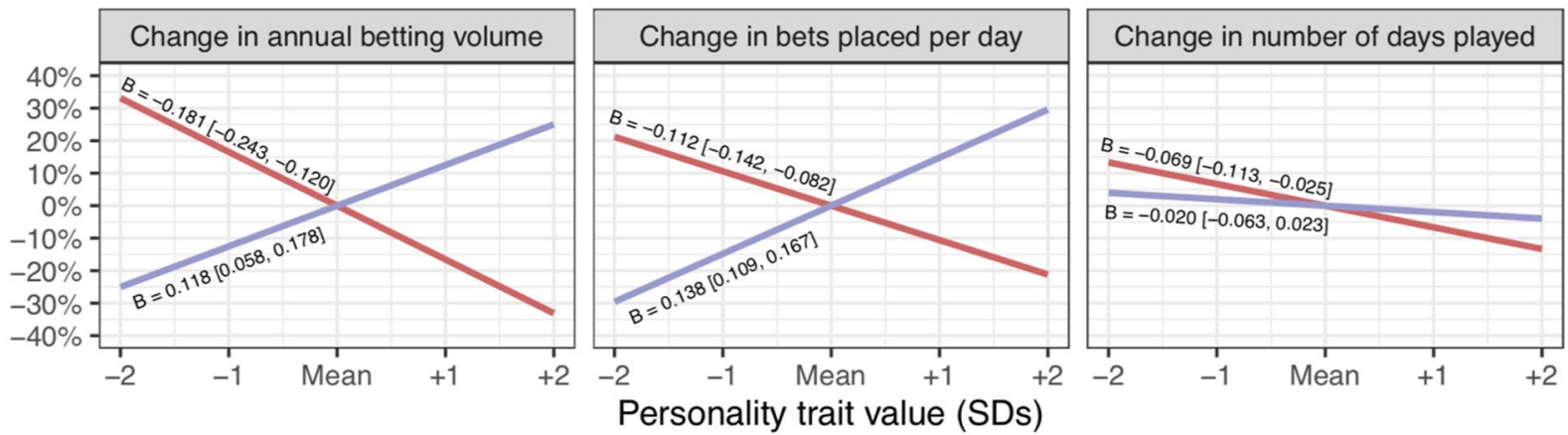

Personality trait value (SDs)

\section{Conscientiousness - Extraversion}

F I G U RE 2 Personality and online horse betting intensity. Top panel: Findings from the raw data on the mean annual betting volume, bets placed per day (both in euros), and number of days played in each personality decile (slopes are fit to decile-level data). Bottom panel: Results from OLS regression model with the above variables log-transformed as DVs, controlling for the effects of various demographic attributes and IQ (see Table 3). The ordinate depicts the change (\%) in respective DVs for individuals with varying Conscientiousness and Extraversion scores (ranging from -2 to +2 standard deviations around the mean) [Color figure can be viewed at wileyonlinelibrary.com]

\section{4 | DISCUSSION}

In the current study, using unique large datasets, we sought to shed light on how Extraversion and Conscientiousness are associated with actual financial decisions (online horse betting) while controlling for various demographic variables and general IQ. We found that self-reported Extraversion was significantly associated with actual betting behavior: higher Extraversion scores predicted a higher likelihood of being a horse race bettor, higher betting volume and more bets placed per day. Similarly, we found that Conscientiousness was negatively associated with all four of our dependent variables: higher Conscientiousness scores predicted a lower likelihood of being a bettor, lower annual betting volume, fewer days played and lower bets placed per day.

Our study made three novel contributions to the existing rich literature on personality and financial risktaking. First, we showed with a nation-wide broad sample $(N>11,000)$ that Conscientiousness and Extraversion have real-life consequences in individual financial decisionmaking. Second, we showed that personality factors have a larger effect on individual financial risk-taking than several demographic variables commonly investigated in gambling studies (Petry, 2005), and, on average, only a slightly lower effect than IQ. Finally, we showed that the personality measurement is a robust predictor of real-life financial behavior, even if measured decades before the actual behavior takes place.

Our findings are consistent with the view of Extraversion as a reflection of general reward seeking tendency (DeYoung, 2015; Smillie, 2013), and in alignment with previous empirical findings on gambling and financial decisions. For example, in the context of poker, Laakasuo et al. (2014) found that Extraversion was positively associated with the number of years spent playing. In a similar vein, Myrseth et al. (2009) showed that need for stimulus intensity and impulsivity specifically predict pathological gambling (i.e., gambling disorder: DSM-5; American Psychiatric Association, 2013); and 


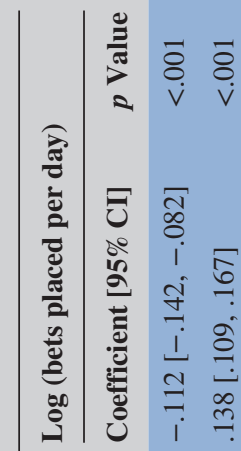

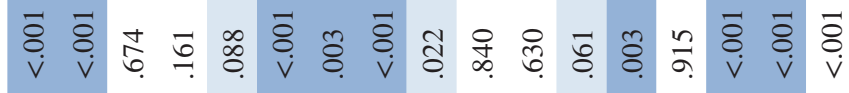

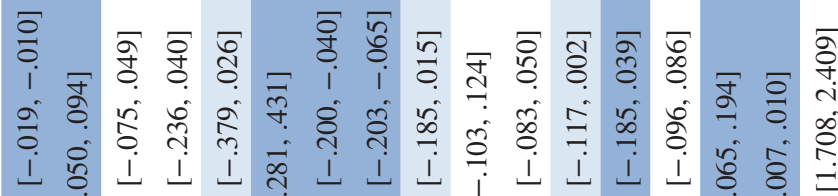

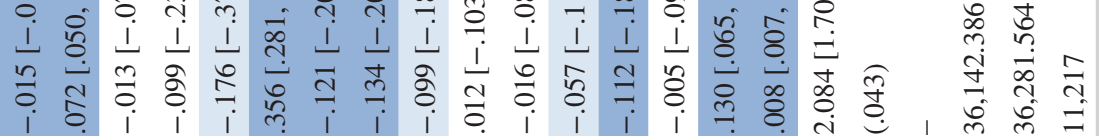

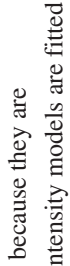

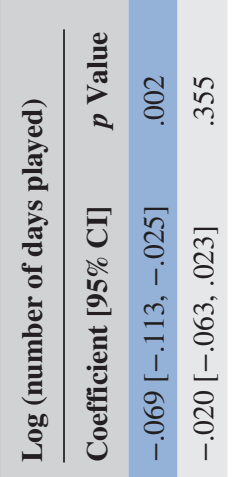

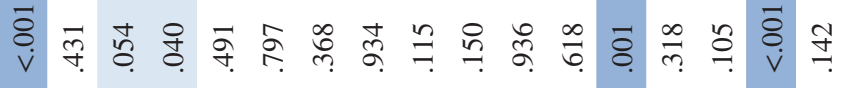

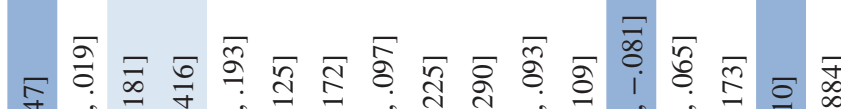

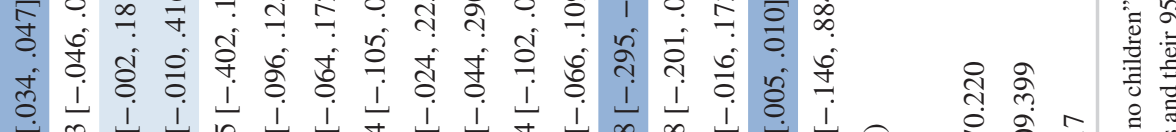

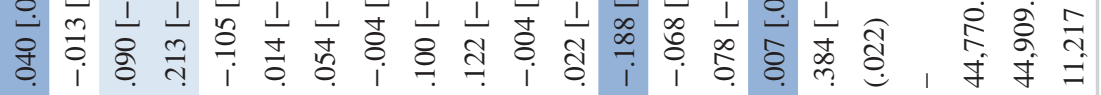

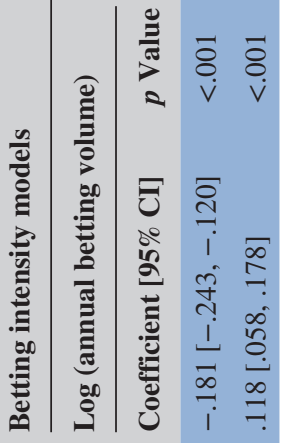

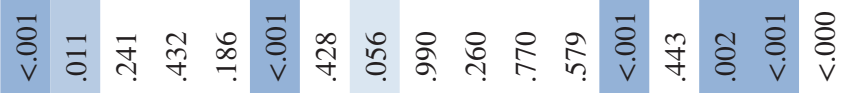

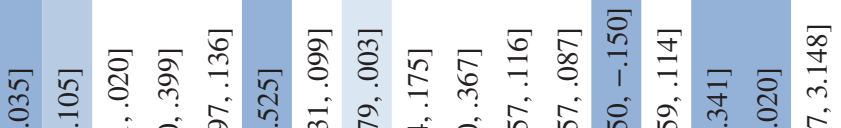

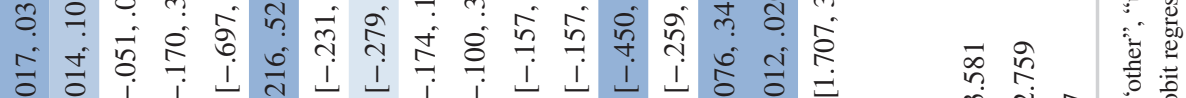



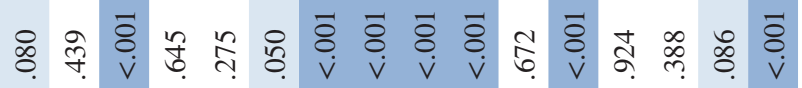



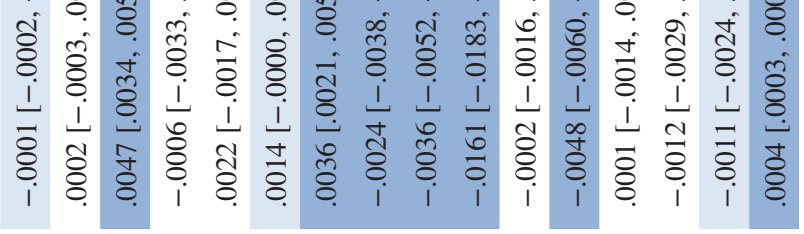

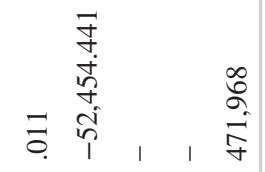

政

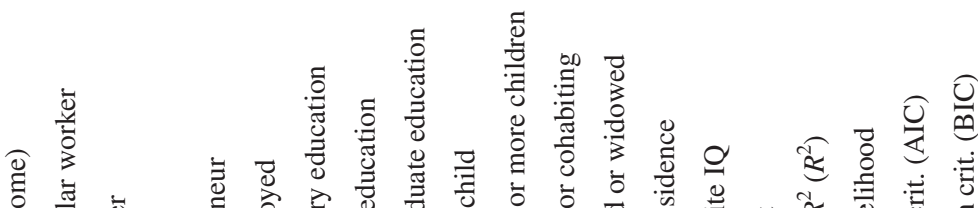

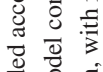
焉这就 
recent evidence from non-WEIRD ${ }^{6}$ samples (see Henrich et al., 2010) has tentatively linked increased tendency to gamble with Extraversion as well (Andrew et al., 2018). Thus, the evidence is accumulating in support of Extraversion as a reward and risk-seeking tendency with real-life financial consequences.

Interestingly, Hanss et al. (2014) found that extraverts do not report more positive attitudes towards gambling compared with introverts; though, the mismatch between selfreported attitudes and actual behaviors has been known for decades. However, the same authors also found that high Conscientiousness is associated with negative attitudes towards frequent gambling, which is in line with our current findings (see also McGrath et al., 2018). In a similar vein, Quigley et al. (2015) found that various childhood adversities together with low consciousness may expose people to excessive gambling. Finally, our results are also in line with a Norwegian study with a large sample size $(N>10,000$; Brunborg et al., 2016) reporting that low Conscientiousness is associated with problem gambling. However, and importantly, our current study stands out from previous work by virtue of observing actual behavior in a real-life setting, instead of relying on self-reported measures for its conclusions.

Indeed, we find it encouraging that self-report measures and actual behavioral data converge on similar conclusions, which is not a given, and tells us that the underlying science is on a sound basis. Similar conclusions have been reached in other domains measuring life-management skills: Conscientiousness is associated with lowered financial risktaking tendencies across different contexts such as asset accumulation (Letkiewicz \& Fox, 2014), investing (Oehler \& Wedlich, 2018) or pension accumulation (Kausel et al., 2016). Our finding - that Conscientiousness may reduce gambling consumption-is generally in line with the theory suggesting that Conscientiousness is about selecting and prioritizing over several goals (DeYoung, 2015; Rueter et al., 2018); being careful and diligent helps individuals control their finances (Bagby et al., 2007; MacLaren et al., 2011).

There may also be alternative explanations to our findings. For example, Ashton et al. (2002) found evidence suggesting that social attention, instead of reward sensitivity, was the central feature of Extraversion. Sociability might explain betting behavior in a live setting; for example, Laakasuo et al. (2014) found that, among poker players, Extraversion was positively linked to preference for "live" as opposed to online play. However, it is unclear how preference for social attention could explain increased betting in an online and predominantly nonsocial environment, though online gambling virtual communities may play a role (e.g., Sirola et al., 2021). It is also unclear whether extraverted individuals are primarily drawn to monetary rewards or to social or reputational rewards involved in skill-based gambling (such as horse betting). Furthermore,
Conscientiousness has been associated with the propensity to follow socially prescribed norms for impulse control (Roberts et al., 2009), conservative political preferences (Carney et al., 2008) and general guilt-proneness (Fayard et al., 2012). As a form of gambling, horse betting may be viewed as reprehensible (going against the norms of "prudent behavior") by individuals with high Conscientiousness, which could explain their reduced gambling intensity. Alternatively, individuals with high Conscientiousness, who strive for well-defined and laid-out goals (Soane et al., 2010), might be aversive specifically to the uncertainty involved in horse betting.

\subsection{Limitations and conclusions}

Although personality is known to be relatively stable across time, the temporal gap between the personality and betting measures may have diluted the observed effects. However, this can also be seen as a strong positive contribution: having such a gap between the measures enabled us to demonstrate that some reasonable effect still persists at least up to 34 years after personality was measured. Moreover, there was no statistically significant interaction between the time since personality was measured and personality traits, suggesting that the predictive power of the traits remains relatively stable across decades - though we note that in our study the gap was at minimum 16 years, and thus the data may not be best suited to evaluate this interaction. The narrow age range in our data (36-53 years) and lack of female participants also makes it difficult to generalize our findings to younger or older populations, or females.

On a similar note, the effect sizes observed were generally modest, even in the models including demographic variables and IQ as predictors. According to meta-analytic evidence, typical statistical effects in personality psychology correspond to, on average, correlations of .21 with a standard deviation of .14; and that correlations of $.1, .2$, and . 3 ought to be considered as relatively small, typical, and relatively large, respectively (Gignac \& Szodorai, 2016; Richard et al., 2003). In the current study, zero-order correlations between personality traits and betting measures were at highest .089, corresponding to small effect sizes per individual predictors. However, we are not aware of any identified predictors that "strongly" or even "moderately" predict gambling behavior across several decades. Furthermore, according to variance decompositions, Extraversion and Conscientiousness were very prominent predictors compared with other covariates, all of which were chosen based on their known associations with gambling- and risk-taking behavior.

To put the results into perspective, the individuals most at risk of betting participation and intense betting - though not necessarily problem gambling - are highly extraverted $(>+2 \mathrm{SD})$ and those very low on Conscientiousness $(<-2 \mathrm{SD})$, 
that is, about $2.5 \%$ of the male population (or $.063 \%$ who have both high Extraversion and low Conscientiousness). For these "at-risk" individuals the probability of being an online horse bettor is only about $3 \%$ higher than for an average person with respect to these traits. To estimate the true extent of the potential harm associated with low Conscientiousness and high Extraversion, more large-scale research is needed, where betting behavior is linked with other life-outcome measures. However, while these effects may appear somewhat modest they nonetheless have significant monetary implications in cumulative betting for those who are bettors: in our analyses, a one $S D$ personality score increase represents an annual decrease or increase of over $€ 570-754$ in spendingroughly a month's rent in Finland, which is a significant amount of money for many people. In a similar vein, Götz et al. (in press) underscore the many dangers of continually demanding large effects in psychological science, and argue that accepting small effects as the norm is the requirement for building a "reliable, reproducible cumulative psychological science". This sentiment is echoed by a study sampling 1,000 psychological articles and finding that effect size was strongly negatively correlated $(r=-.45)$ with sample size, suggesting that larger samples reveal effect sizes closer to the true effect size (Kühberger et al., 2014).

We also note that the FDF data do not directly map onto existing contemporary models of personality, and the links between betting intensity and the remaining FFM traits (Neuroticism, Agreeableness and Openness) remain shrouded. It is also good to keep in mind the scale and scope of the results when interpreting their implications in terms of potential psychopathologies. We did not evaluate whether Extraversion, even in its extremes, exposes people to gambling related psychopathologies, since there were no measures of problem gambling in the data. In fact, Extraversion has many health benefits that recent research has uncovered (i.e., social support networks, reduced loneliness, etc.; Denworth, 2020), which may buffer against gambling related harms. High gambling frequency alone does not necessarily lead to problem gambling or gambling disorder, and our study thus does not offer direct evidence on the adverse (or beneficial) effects of gambling.

Finally, some local urban "army tales" suggest that some people may lie and intentionally mislead in the FDF tests to avoid being sent to further officer training, which inevitably lengthens the conscription period from 6 to 12 months (though there is no hard evidence of this, the topic occasionally surfaces in mainstream media). Contrary to common controlled psychological experiments, there may be real life consequences for telling the truth in the FDF tests.

Despite the potential limitations, our measures supported existing theories of Conscientiousness and Extraversion as relevant, sensible and robust personality constructs. Our study is the first to combine large datasets on actual gambling behavior and personality measures, and as such could pave the way for future work combining large registry-based datasets. Importantly, the personality factors, just like IQ, were robust predictors of betting behavior even when measured 16-34 years ago, and on average more significant than many known demographic covariates in gambling studies.

\section{ACKNOWLEDGMENTS}

The authors (NS, JS, TK) greatly appreciate the financial support from Emil Aaltonen foundation, the Academy of Finland (grant \#331102), and (JP, NS, JS, TK) from the Finnish Foundation for Alcohol Studies, which also covered the research meeting travel costs for SC and JP without honoraria. ML greatly appreciates the generous grants by Jane and Aatos Erkko Foundation and the Academy of Finland (grant \#323207). The funders were not involved in the study design, data analysis or data interpretation or in any phase of the publication process. We thank the Finnish Defence Forces (research permit \#AM13766) for the IQ and personality traits data, Fintoto Ltd for providing the horse betting data, and Statistics Finland for the socioeconomic registry data (license \#TK53-1048-16). We also thank Mika Koverola, Teemu Saikkonen, and Professor Markus Jokela for valuable comments on our manuscript.

\section{ORCID}

Jussi Palomäki (D) https://orcid.org/0000-0001-6063-0926

\section{ENDNOTES}

${ }^{1}$ Self-confidence was additionally strongly correlated with lower Neuroticism (being less prone to anxiety, worry, and other emotions); and lower Agreeableness was associated with higher leadership motivation and achievement striving.

2 The log-transform successfully normalized "betting volume" and "bets place per day". However, "number of days played" was not fully normalized, but the results obtained with a log-transformed DV relating to IVs were qualitatively similar to those obtained with an untransformed DV.

${ }^{3}$ Specifically, we used the $r$-scale value of .3535 , which is a default scale for the Cauchy prior (Rouder \& Morey, 2012; Liang et al., 2008). The value is chosen in a way that the researcher assumes a $50 \%$ chance of observing an absolute effect (which can be expressed in terms of Cohen's $d$ ) larger than the chosen scale value. The value .3535 corresponds to an $R^{2}$ value of .03 . However, we also ran the same analysis using an $r$-scale value of .2 (corresponding to an $R^{2}$ value of .01), finding the same pattern of results. See also http://danie llakens.blogspot.com/2016/01/power-analysis-for-default-bayesian-t. html for further discussion on a similar topic. Note that this method could not unambiguously be applied for probit models.

${ }^{4}$ In participation model (a probit model), an increase of one standard deviation in a personality trait measure predicts $(\beta \times S D) \times 100$ percentage point change in average participation rate. For instance, one $S D$ increase in Conscientiousness predicts, on average, $(-0.0048 \times 1) * 100=-0.48$ percentage points lower participation rate.

${ }^{5}$ In Betting intensity models (OLS models), an increase of one standard deviation in a personality trait measure predicts $\left(\mathrm{e}^{\beta \times S D}-1\right) \times 100$ 
percentage change in the dependent variable. For instance, one $S D$ increase in Conscientiousness in $\log$ (Annual betting volume)-model predicts, on average, $\left(\mathrm{e}^{-0.181 \times 1}-1\right) * 100 \approx-16.56$ percentage points lower betting volume.

${ }^{6}$ Western, Educated, Industrialized, Rich and Democratic.

\section{REFERENCES}

Adelstein, J. S., Shehzad, Z., Mennes, M., DeYoung, C. G., Zuo, X. N., Kelly, C., Margulies, D. S., Bloomfield, A., Gray, J. R., Castellanos, F. X., \& Milham, M. P. (2011). Personality is reflected in the brain's intrinsic functional architecture. PLOS ONE, 6(11), e27633.

American Psychiatric Association. (2013). Diagnostic and statistical manual of mental disorders (5th ed.). Author.

Andrew, N. O., Judith, O., \& Benard, M. (2018). Relationship between Extraversion and gambling tendencies among students in Nyamira south-sub-county, Kenya. International Journal of Novel Research in Education and Learning, 5(3), 73-83.

Armstrong, A. R., \& Carroll, M. (2017). Race betting in Australia. Australian Gambling Research Centre, Australian Institute of Family Studies.

Ashton, M. C., Lee, K., \& Paunonen, S. V. (2002). What is the central feature of Extraversion? Social attention versus reward sensitivity. Journal of Personality and Social Psychology, 83(1), 245-252. https://doi.org/10.1037/0022-3514.83.1.245

Bagby, R. M., Vachon, D. D., Bulmash, E. L., Toneatto, T., Quilty, L. C., \& Costa, P. T. (2007). Pathological gambling and the five-factor model of personality. Personality and Individual Differences, 43(4), 873-880. https://doi.org/10.1016/j.paid.2007.02.011

Beck, E. D., \& Jackson, J. J. (2020). Consistency and change in idiographic personality: A longitudinal ESM network study. Journal of Personality and Social Psychology, 118(5), 1080-1100. https://doi. org/10.1037/pspp0000249

Berridge, K. C., \& Robinson, T. E. (1998). What is the role of dopamine in reward: Hedonic impact, reward learning, or incentive salience? Brain Research Reviews, 28(3), 309-369. https://doi.org/10.1016/ S0165-0173(98)00019-8

Blaszczynski, A., \& Nower, L. (2002). A pathways model of problem and pathological gambling. Addiction, 97(5), 487-499. https://doi. org/10.1046/j.1360-0443.2002.00015.x

Brunborg, G. S., Hanss, D., Mentzoni, R. A., Molde, H., \& Pallesen, S. (2016). Problem gambling and the five-factor model of personality: A large population-based study. Addiction, 111(8), 1428-1435. https://doi.org/10.1111/add.13388

Carney, D. R., Jost, J. T., Gosling, S. D., \& Potter, J. (2008). The secret lives of liberals and conservatives: Personality profiles, interaction styles, and the things they leave behind. Political Psychology, 29(6), 807-840. https://doi.org/10.1111/j.1467-9221.2008.00668.x

Castanier, C., Scanff, C. L., \& Woodman, T. (2010). Who takes risks in high-risk sports? A typological personality approach. Research Quarterly for Exercise and Sport, 81(4), 478-484. https://doi. org/10.1080/02701367.2010.10599709

Civai, C., Hawes, D. R., DeYoung, C. G., \& Rustichini, A. (2016). Intelligence and Extraversion in the neural evaluation of delayed rewards. Journal of Research in Personality, 61, 99-108. https://doi. org/10.1016/j.jrp.2016.02.006

Cotte, J. (1997). Chances, trances, and lots of slots: Gambling motives and consumption experiences. Journal of Leisure Research, 29(4), 380-406. https://doi.org/10.1080/00222216.1997.11949805
Damian, R. I., Spengler, M., Sutu, A., \& Roberts, B. W. (2019). Sixteen going on sixty-six: A longitudinal study of personality stability and change across 50 years. Journal of Personality and Social Psychology, 117(3), 674-695. https://doi.org/10.1037/pspp0000210

Davis, C., Patte, K., Tweed, S., \& Curtis, C. (2007). Personality traits associated with decision-making deficits. Personality and Individual Differences, 42(2), 279-290. https://doi.org/10.1016/j. paid.2006.07.006

Denworth, L. (2020). Friendship: The evolution, biology, and extraordinary power of life's fundamental bond. WW Norton \& Company.

Depue, R. A. (1995). Neurobiological factors in personality and depression. European Journal of Personality, 9, 413-439. https://doi. org/10.1002/per.2410090509

Depue, R. A., \& Collins, P. F. (1999). Neurobiology of the structure of personality: Dopamine, facilitation of incentive motivation, and Extraversion. Behavioral and Brain Sciences, 22(3), 491-517. https://doi.org/10.1017/S0140525X99002046

Devos, M. G., Clark, L., Bowden-Jones, H., Grall-Bronnec, M., ChalletBouju, G., Khazaal, Y., Maurage, P., \& Billieux, J. (2020). The joint role of impulsivity and distorted cognitions in recreational and problem gambling: A cluster analytic approach. Journal of Affective Disorders, 260, 473-482. https://doi.org/10.1016/j.jad.2019.08.096

DeYoung, C. G. (2015). Cybernetic big five theory. Journal of Research in Personality, 56, 33-58.

DeYoung, C. G., Shamosh, N. A., Green, A. E., Braver, T. S., \& Gray, J. R. (2009). Intellect as distinct from Openness: Differences revealed by fMRI of working memory. Journal of Personality and Social Psychology, 97(5), 883-892. https://doi.org/10.1037/a0016615

Dunbar, R. I. (1998). The social brain hypothesis. Evolutionary Anthropology: Issues, News, and Reviews: Issues, News, and Reviews, 6(5), 178-190.

European Gaming and Betting Association. (2018). Europe's Online Gambling Market Grew 11\% in 2018-New Data Confirms. https:// www.egba.eu/news-post/europes-online-gambling-market-grew11-in-2018-new-data-confirms/

Fayard, J. V., Roberts, B. W., Robins, R. W., \& Watson, D. (2012). Uncovering the affective core of Conscientiousness: The role of selfconscious emotions. Journal of Personality, 80(1), 1-32. https://doi. org/10.1111/j.1467-6494.2011.00720.x

Fisher, R. J. (1993). Social desirability bias and the validity of indirect questioning. Journal of Consumer Research, 20(2), 303-315. https://doi.org/10.1086/209351

Fishman, I., Ng, R., \& Bellugi, U. (2011). Do extraverts process social stimuli differently from introverts? Cognitive Neuroscience, 2(2), 67-73. https://doi.org/10.1080/17588928.2010.527434

Fox, M. D., Corbetta, M., Snyder, A. Z., Vincent, J. L., \& Raichle, M. E. (2006). Spontaneous neuronal activity distinguishes human dorsal and ventral attention systems. Proceedings of the National Academy of Sciences, 103(26), 10046-10051.

Gignac, G. E., \& Szodorai, E. T. (2016). Effect size guidelines for individual differences researchers. Personality and Individual Differences, 102, 74-78. https://doi.org/10.1016/j.paid.2016.06.069

Götz, F., Gosling, S., \& Rentfrow, J. (in press). Small effects: The indispensable foundation for a cumulative psychological science. Perspectives on Psychological Science.

Hanss, D., Mentzoni, R. A., Delfabbro, P., Myrseth, H., \& Pallesen, S. (2014). Attitudes toward gambling among adolescents. International Gambling Studies, 14(3), 505-519. https://doi.org/10.1080/14459 795.2014.969754 
Henrich, J., Heine, S. J., \& Norenzayan, A. (2010). The weirdest people in the world? Behavioral and Brain Sciences, 33(2-3), 61-83. https://doi.org/10.1017/S0140525X0999152X

Hodgins, D. C., \& Holub, A. (2015). Components of impulsivity in gambling disorder. International Journal of Mental Health and Addiction, 13(6), 699-711.

Ishfaq, M., Nazir, M. S., Qamar, M. A. J., \& Usman, M. (2020). Cognitive bias and the Extraversion personality shaping the behavior of investors. Frontiers in Psychology, 11, 2513. https://doi. org/10.3389/fpsyg.2020.556506

Jokela, M., Pekkarinen, T., Sarvimäki, M., Terviö, M., \& Uusitalo, R. (2017). Secular rise in economically valuable personality traits. Proceedings of the National Academy of Sciences, 114(25), 6527-6532.

Kapogiannis, D., Sutin, A., Davatzikos, C., Costa, P., Jr., \& Resnick, S. (2013). The five factors of personality and regional cortical variability in the Baltimore longitudinal study of aging. Human Brain Mapping, 34(11), 2829-2840. https://doi.org/10.1002/hbm.22108

Karre, P. R., Mottus, R., \& Konstabel, K. (2009). Pathological gambling in Estonia: Relationships with personality, self-esteem, emotional states and cognitive ability. Journal of Gambling Studies, 25, $377-$ 390. https://doi.org/10.1007/s10899-009-9119-y

Kausel, E. E., Hansen, E., \& Tapia, P. (2016). Responsible personal finance: The role of Conscientiousness in bank and pension savings in Chile. International Review of Finance, 16(1), 161-167. https:// doi.org/10.1111/irfi.12069

Killick, E. A., \& Griffiths, M. D. (2021). Why do individuals engage in in-play sports betting? A qualitative interview study. Journal of Gambling Studies, 37(1), 221-240. https://doi.org/10.1007/s10899020-09968-9

Kühberger, A., Fritz, A., \& Scherndl, T. (2014). Publication bias in psychology: A diagnosis based on the correlation between effect size and sample size. PLoS ONE, 9(9), e105825. https://doi.org/10.1371/ journal.pone.0105825

Laakasuo, M., Palomäki, J., \& Salmela, M. (2014). Experienced poker players are emotionally stable. Cyberpsychology, Behavior, and Social Networking, 17(10), 668-671. https://doi.org/10.1089/ cyber.2014.0147

Leeman, R. F., \& Potenza, M. N. (2012). Similarities and differences between pathological gambling and substance use disorders: A focus on impulsivity and compulsivity. Psychopharmacology, 219(2), 469-490. https://doi.org/10.1007/s00213-011-2550-7

Letkiewicz, J. C., \& Fox, J. J. (2014). Conscientiousness, financial literacy, and asset accumulation of young adults. Journal of Consumer Affairs, 48(2), 274-300. https://doi.org/10.1111/ joca. 12040

Lewis, G. J., Dickie, D. A., Cox, S. R., Karama, S., Evans, A. C., Starr, J. M., Bastin, M. E., Wardlaw, J. M., \& Deary, I. J. (2018). Widespread associations between trait Conscientiousness and thickness of brain cortical regions. NeuroImage, 176, 22-28. https://doi.org/10.1016/j. neuroimage.2018.04.033

Liang, F., Paulo, R., Molina, G., Clyde, M. A., \& Berger, J. O. (2008). Mixtures of g priors for Bayesian variable selection. Journal of the American Statistical Association, 103(481), 410-423.

Lucas, R. E., Diener, E., Grob, A., Suh, E. M., \& Shao, L. (2000). Crosscultural evidence for the fundamental features of Extraversion. Journal of Personality and Social Psychology, 79(3), 452-468. https://doi.org/10.1037/0022-3514.79.3.452

MacLaren, V. V., Fugelsang, J. A., Harrigan, K. A., \& Dixon, M. J. (2011). The personality of pathological gamblers: A meta-analysis.
Clinical Psychology Review, 31(6), 1057-1067. https://doi. org/10.1016/j.cpr.2011.02.002

Mao, T., Pan, W., Zhu, Y., Yang, J., Dong, Q., \& Zhou, G. (2018). Self-control mediates the relationship between personality trait and impulsivity. Personality and Individual Differences, 129, 70-75. https://doi.org/10.1016/j.paid.2018.03.013

McGrath, D. S., Neilson, T., Lee, K., Rash, C. L., \& Rad, M. (2018). Associations between the HEXACO model of personality and gambling involvement, motivations to gamble, and gambling severity in young adult gamblers. Journal of Behavioral Addictions, 7(2), 392400. https://doi.org/10.1556/2006.7.2018.29

Merritt, C. J., \& Tharp, I. J. (2013). Personality, self-efficacy and risktaking in parkour (free-running). Psychology of Sport and Exercise, 14(5), 608-611. https://doi.org/10.1016/j.psychsport.2013.03.001

Moffitt, T. E., Arseneault, L., Belsky, D., Dickson, N., Hancox, R. J., Harrington, H., Houts, R., Poulton, R., Roberts, B. W., Ross, S., Sears, M. R., Thomson, W. M., \& Caspi, A. (2011). A gradient of childhood self-control predicts health, wealth, and public safety. Proceedings of the National Academy of Sciences, 108(7), 26932698. https://doi.org/10.1073/pnas.1010076108

Mora-Salgueiro, J., García-Estela, A., Hogg, B., Angarita-Osorio, N., Amann, B. L., Carlbring, P., Jiménez-Murcia, S., Pérez-Sola, V., \& Colom, F. (2021). The prevalence and clinical and sociodemographic factors of problem online gambling: A systematic review. Journal of Gambling Studies, Advance Online Publication. https:// doi.org/10.1007/s10899-021-09999-w

Myrseth, H., Pallesen, S., Molde, H., Johnsen, B. H., \& Lorvik, I. M. (2009). Personality factors as predictors of pathological gambling. Personality and Individual Differences, 47(8), 933-937. https://doi. org/10.1016/j.paid.2009.07.018

Nicholson, N., Soane, E., Fenton-O'Creevy, M., \& Willman, P. (2005). Personality and domain-specific risk taking. Journal of Risk Research, 8(2), 157-176. https://doi.org/10.1080/1366987032 000123856

Nower, L., \& Blaszczynski, A. (2006). Impulsivity and pathological gambling: A descriptive model. International Gambling Studies, 6(1), 61-75. https://doi.org/10.1080/14459790600644192

Nyman, K. (2007). Varusmiesten johtajavalintojen luotettavuus [The reliability of conscript leader selection] (Publishing Series Vol. 1). Finnish Defence Forces Education Development Centre.

O'Connor, M. C., \& Paunonen, S. V. (2007). Big Five personality predictors of post-secondary academic performance. Personality and Individual Differences, 43(5), 971-990. https://doi.org/10.1016/j. paid.2007.03.017

Oehler, A., \& Wedlich, F. (2018). The relationship of Extraversion and Neuroticism with risk attitude, risk perception, and return expectations. Journal of Neuroscience, Psychology, and Economics, 11(2), 63-92. https://doi.org/10.1037/npe0000088

Oehler, A., Wendt, S., Wedlich, F., \& Horn, M. (2018). Investors' personality influences investment decisions: Experimental evidence on Extraversion and Neuroticism. Journal of Behavioral Finance, 19(1), 30-48. https://doi.org/10.1080/15427560.2017.1366495

Parke, A., \& Parke, J. (2019). Transformation of sports betting into a rapid and continuous gambling activity: A grounded theoretical investigation of problem sports betting in online settings. International Journal of Mental Health and Addiction, 17, 1340-1359. https://doi. org/10.1007/s11469-018-0049-8

Paul, R. J., \& Weinbach, A. P. (2011). Baseball: A poor substitute for football-More evidence of sports gambling as consumption. Journal of Sports Economics, 14(2), 115-132. 
Petry, N. M. (2005). Pathological gambling: Etiology, comorbidity, and treatment (Vol. 2). American Psychological Association.

Quigley, L., Yakovenko, I., Hodgins, D. C., Dobson, K. S., el-Guebaly, N., Casey, D. M., Currie, S. R., Smith, G. J., Williams, R. J., \& Schopflocher, D. P. (2015). Comorbid problem gambling and major depression in a community sample. Journal of Gambling Studies, 31(4), 1135-1152. https://doi.org/10.1007/s10899-014-9488-8

Richard, F. D., Bond, C. F., Jr., \& Stokes-Zoota, J. J. (2003). One hundred years of social psychology quantitatively described. Review of General Psychology, 7(4), 331-363. https://doi.org/10.1037/108 9-2680.7.4.331

Roberts, B. W., \& DelVecchio, W. F. (2000). The rank-order consistency of personality traits from childhood to old age: A quantitative review of longitudinal studies. Psychological Bulletin, 126(1), 3-25. https://doi.org/10.1037/0033-2909.126.1.3

Roberts, B. W., Jackson, J. J., Fayard, J. V., Edmonds, G., \& Meints, J. (2009). Conscientiousness. In M. R. Leary \& R. H. Hoyle (Eds.), Handbook of individual differences in social behavior (pp. 369381). The Guilford Press.

Roberts, B. W., Walton, K. E., \& Viechtbauer, W. (2006). Patterns of mean-level change in personality traits across the life course: A meta-analysis of longitudinal studies. Psychological Bulletin, 132(1), 1-25. https://doi.org/10.1037/0033-2909.132.1.1

Robins, R. W., Fraley, R. C., Roberts, B. W., \& Trzesniewski, K. H. (2001). A longitudinal study of personality change in young adulthood. Journal of Personality, 69(4), 617-640. https://doi.org/10.11 11/1467-6494.694157

Rodríguez, P., Humphreys, B. R., \& Simmons, R. (2017). Economics of sports betting. Edward Elgar.

Rouder, J. N., \& Morey, R. D. (2012). Default Bayes factors for model selection in regression. Multivariate Behavioral Research, 47(6), 877-903.

Rueter, A. R., Abram, S. V., MacDonald, A. W., III, Rustichini, A., \& DeYoung, C. G. (2018). The goal priority network as a neural substrate of Conscientiousness. Human Brain Mapping, 39(9), 35743585. https://doi.org/10.1002/hbm.24195

Salonen, A., Lind, K., Hagfors, H., Castrén, S., \& Kontto, J. (2020). Gambling, problem gambling and attitudes and opinions towards gambling in 2007-2019: Finnish Gambling 2019. Finnish Institute for Health and Welfare (THL), Report 18/2020.

Savage, J. E., Slutske, W. S., \& Martin, N. G. (2014). Personality and gambling involvement: A person-centered approach. Psychology of Addictive Behaviors, 28(4), 1198-1211. https://doi.org/10.1037/ a0037413

Sirola, A., Savela, N., Savolainen, I., Kaakinen, M., \& Oksanen, A. (2021). The role of virtual communities in gambling and gaming behaviors: A systematic review. Journal of Gambling Studies, 37(1), 165-187. https://doi.org/10.1007/s10899-020-09946-1

Smillie, L. D. (2013). Extraversion and reward processing. Current Directions in Psychological Science, 22(3), 167-172. https://doi. org/10.1177/0963721412470133

Smillie, L. D., Cooper, A. J., \& Pickering, A. D. (2011). Individual differences in reward-prediction-error: Extraversion and feedbackrelated negativity. Social Cognitive and Affective Neuroscience, 6(5), 646-652. https://doi.org/10.1093/scan/nsq078

Soane, E., Dewberry, C., \& Narendran, S. (2010). The role of perceived costs and perceived benefits in the relationship between personality and risk-related choices. Journal of Risk Research, 13(3), 303-318. https://doi.org/10.1080/13669870902987024

Suhonen, N., Saastamoinen, J., Forrest, D., \& Kainulainen, T. (2020). Is gambling a tax on stupidity? Working paper. http://www.imlab. ac.uk/media/livacuk/schoolofmanagement/research/economics/ Is,gambling,a,tax,on,stupidity.pdf

Thomas Yeo, B. T., Krienen, F. M., Sepulcre, J., Sabuncu, M. R., Lashkari, D., Hollinshead, M., Roffman, J. L., Smoller, J. W., Zöllei, L., Polimeni, J. R., Fischl, B., Liu, H., \& Buckner, R. L. (2011). The organization of the human cerebral cortex estimated by intrinsic functional connectivity. Journal of Neurophysiology, 106, 1125-1165.

Wacker, J., \& Smillie, L. D. (2015). Trait Extraversion and dopamine function. Social and Personality Psychology Compass, 9(6), 225238. https://doi.org/10.1111/spc3.12175

Wong, A., \& Carducci, B. (2013). Does personality affect personal financial risk tolerance behavior? IUP Journal of Applied Finance, 19(3), 5-18.

Wu, C. C., Samanez-Larkin, G. R., Katovich, K., \& Knutson, B. (2014). Affective traits link to reliable neural markers of incentive anticipation. NeuroImage, 84, 279-289. https://doi.org/10.1016/j.neuro image.2013.08.055

\section{SUPPORTING INFORMATION}

Additional Supporting Information may be found online in the Supporting Information section.

How to cite this article: Palomäki J, Laakasuo M, Castrén S, Saastamoinen J, Kainulainen T, Suhonen N. Online betting intensity is linked with Extraversion and Conscientiousness. J Pers. 2021;89:1081-1094. https:// doi.org/10.1111/jopy. 12637 